\title{
ENTRE EL ADAN Y EL GOLEM, A PROPOSITO DE UN POEMA DE JORGE LUIS BORGES
}

\author{
Kattia Cbinchilla Sánchez
}

\begin{abstract}
In the Jorge Luis Borges' literature producction, there is a little poem called "El Golemm", wich remit us to the tradition of the hebrew Kabbala. This article pretends to show a mythic-symbolic dimension in the binomials GOD-CRIATURE, GOD-ADAM, MAN-MONSTER, RABBINGOLEM.
\end{abstract}

\section{Prolegómenos}

Una mañana, en uno de los cursos complementarios para la Licenciatura, la doctora Clara Corneli Marochi nos leyó un poema de Jorge Luis Borges: "El Golem". Aquel enigmático nombre produciría un arcano imborrable en la memoria el cual retomamos aquí. A través de su corta extensión, el lector incursiona en el mundo de la Cábala práctica, el mundo mágico de la palabra, del Logos, Verbo Divino de la creación.

Esencialmente, el Golem es una especie de hombre artificial, creado por medios mágicos, tomando como base la creación de Adán. Así, pues, una idea fluctúa en el ambiente: el bimonio Dios-hombre y el binomio homólogo Creador-criatura. En esta relación, se estará pensando en la estructura básica del poder (dominador-dominado) y, por ende, en el sueño ancestral del hombre, como demiurgo cosmogónico, capaz de crear un ser semejante a él, para encomendarle labores serviles y dominarlo enteramente. No omito manifestar que tales aseveraciones son vistas a partir de una postura un tanto impía, pero es nuestra
"Comprende - hombre- que eres otro mundo en pequeño y que en ti se hallan el sol, la luna y también las estrellas".

Origenes

labor, en el presente artículo, despojarnos de cualquier consideración o reflexión teológica. Por lo cual, lejos de todo subjetivismo, afirmamos que Dios creó al hombre y el rabino cabalista creó a su Golem, gracias ala imitación del acto generador divino. Empero, el Golem es mudo, el hombre es incapaz de darle el don de la palabra.

La vetusta ambición humana de "crear" por sí mismo, redunda en el principio mimético de la gran obra del Hacedor. Toda creación es un ordenamiento del caos primigenio. La historia sagrada —entiéndase mito- nos revela cómo fue creado el mundo y, por lógica, el hombre. Eliade nos dice, a este respecto:

"En general, se puede afirmar que todo mito relata cómo algo llegó a existir: el mundo, el hombre, una especie animal, una institución social. Por el mismo hecho de que la creación del mundo precede a todo lo demás, la cosmogonía goza de un prestigio especial"."

El hombre de la Cábala sabe que hay un misterio insondable en las Sagradas Escrituras, misterio que debe descubrir y podría utilizar. El alfabeto hebraico, dictado por el Hacedor, consta de veintidós letras, que constituyen 
veintidós sustancias primitivas y allí radica la potencia creadora que el hombre no puede conocer.

\begin{abstract}
"Ninguna personas conoce su orden (verdadero), pues los parágrafos de la Thora (la ley) no están indicados en su orden justo. De otro modo, cualquiera que las leyera podría crear un mundo, animar a los muertos y bacer milagros. Por esto el orden de la Thora está oculto y no lo conoce nadie más que Dios"'.
\end{abstract}

Dado lo anterior, la Cábala -doctrina mística de los hebreos- considera que Dios crea el universo de él mismo, él está en el fondo de todas las cosas y todo existe en él. De allí, la búsqueda de la palabra perdida (Yahvé), del nombre inefable de Dios, nombre único capaz de activar el proceso cosmogónico.

"Y, hecho de consonantes y vocales habrá un terrible Nombre, que la esencia cifre de Dios y que la Omnipotencia guarda en letras y sílabas cabales"s.

\section{Adán: la divina creación}

Adán es la gran creación, el primer hombre, hecho a la imagen y semejanza de Dios. Es la culminación de la obra cosmogónica, primo prior, el más hombre de todos los hombres. En sintesis, es el hombre primordial, "representación extensiva de la fuerza del universo"14. Etimológicamente, ciertos filólogos, hablan de 'adama': tierra rojiza. Lo cual nos remite al Adán Rojo, el andrógino, el ser primigenio antes de la separación del lado derecho y izquierdo (Ysha, Eva, la mujer)s:

"... y los dos vendrán a ser una sola carne"6.

Desde esta perspectiva, luego de la partición del andrógino primordial, da inicio el proceso de caída: expulsados el hombre y la mujer, ningún ser tiene acceso al Edén. El Paraíso queda prohibido para su descendencia. Empero, sólo algunos iniciados habían penetrado en el territorio edénico. Seth, tercer hijo de Adán, fue el primero y salió en busca del misterioso Grial.

De igual manera, Adán como primer ente, conocería el sagrado nombre, clave y esencia de la creación:

"Adán y las estrellas lo supieron en el Jardín. La herrumbre del pecado (dicen los cabalistas) lo han borrado y las generaciones lo perdieron"?
La Cábala distingue dos Adanes: el Adán Celestial, el hombre primordial, el Adán Kadmon, y el Adán terreno, padre de la especie, el 'protoplasta' (el Adán Letatah, para ciertos ocultistas). Según la tradición, tras la contracción del Ain-Soph, la primera emanación fue Adán Kadmon, algo como el Logos divino, el Verbo. Este es el hombre universal cuya misión sería dar testimonio de la gloria de Dios. La luz cegadora de los Sefirot surge de los ojos, la nariz, la boca y las orejas de Adán Kadmon. Anteriormente, esa luz era indiferenciada y reposaba en el seno de los Sefirot. Así, se da una división de estos Sefirot, la cual es contenida primeramente por unos "vasos" (Kelim). Sin embargo, los vasos sólo resisten el impacto de los tres primeros, por lo cual, los seis restantes destruyen tales contenedores. Esta ruptura de vasos (Chevirath ha Kelim), dio inicio a la Caída y a la Manifestación; los rayos de luz se mezclan con el mal preexistente.

La luz divina de los Sefirot se reorganizó a través del Adán Kadmon. Cada Sefirot se transformó en un atributo divino, un "rostro" de Dios (Parsuf). Tal y como puede apreciarse, el Adán Kadmon es un estructura de axis mundi, un árbol cósmico, a partir de una reorganización del principio cosmogónico.

Asimismo, el árbol cósmico es idéntico al templo-palacio y a la montaña cósmica, puesto que, por un eje latente, se organiza la realidad en CIELO-TIERRA-INFIERNO.

"El 'lugar sagrado' es un microcosmos porque repite el paisaje cósmico, porque es un reflejo del todo. El altar y el tiempo (...) sus transformaciones ulteriores del 'lugar sagrado' primitivo, son a su vez microcosmos, porque son centros del mundo, porque está en el corazón mismo del universo y constituyen una imago mundi"s.

Adán Kadmon resume el plan de los mundos celeste, cósmico y terrenal. Es es el 'ánthropos', el hijo del Padre, prototipo, pero no ejecutor, como lo sería un Demiurgo. No es el mero arquetipo humano, este último papel lo cumple el Adán protoplasta, el Adán bíblico que vivió hasta los 930 años?.

Adán Kadmon testimonia la misión del hombre, cual es conservar, en todo su esplendor, la primera emanación de Dios. Al traicionar tal misión, el Adán terrenal y su descendencia no fueron más que un reflejo ensombrecido del Adán celestial. El polo opuesto de Adán 
Relaciones entre el árbol de la vida y Adán Kadmon

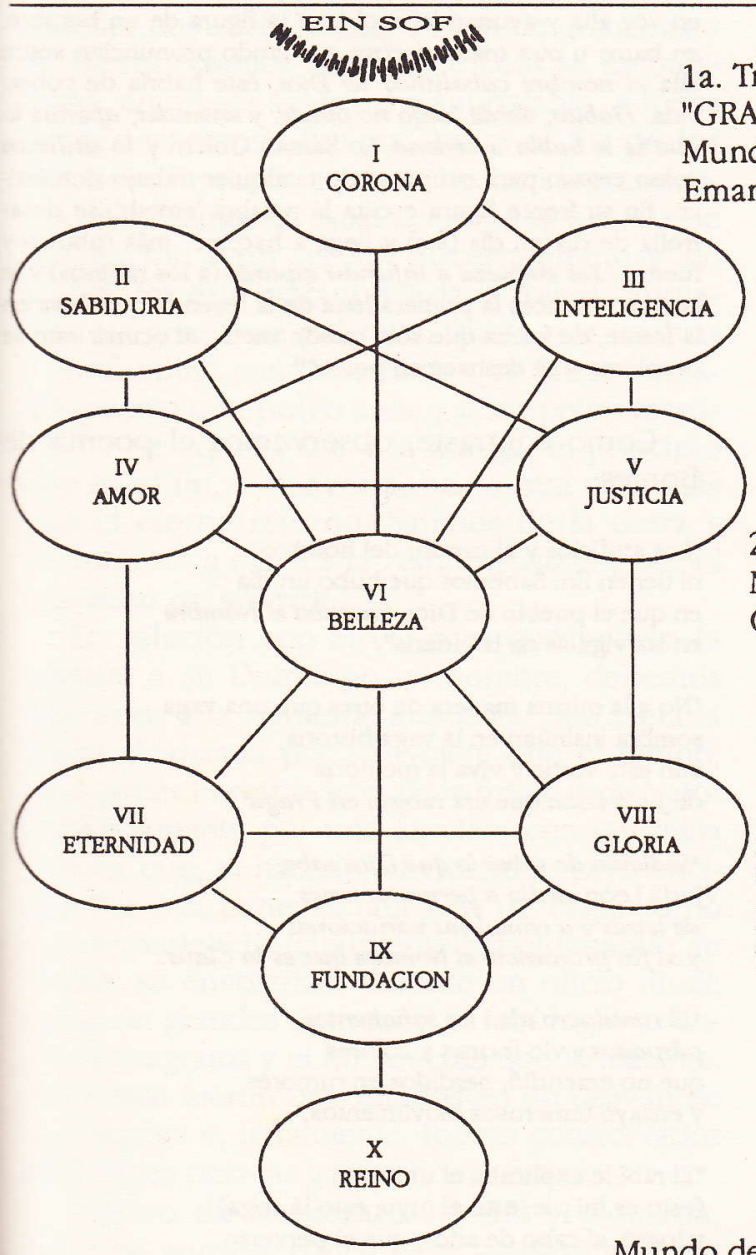

2a. Tríada Mundo de la Creación

3a. Tríada "PEQUEÑO ROSTRO" Mundo de la Formación

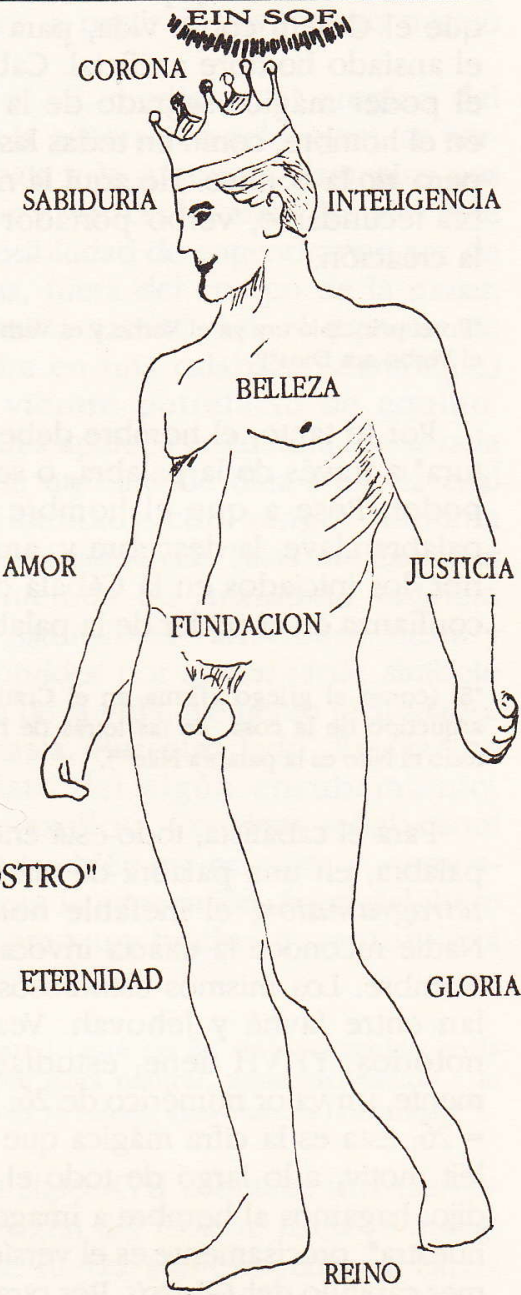

Kadmon, es el Adán Belial, la emanación tenebrosa, según ciertos ocultistas. Adán Belial no es el diablo, pese a que en la demonología occidental figura como uno de los Príncipes de la Tinieblas. Más bien, debe considerársele como génesis del Infierno. Así como Adán Kadmon es el prototipo del Hombre celestial, Adán Belial es el arquetipo del Hombre infernal.

\section{Golem: la humana creación}

Durante la Edad Media, aparece en Alemania un movimiento místico llamado jasidismo, fundado por el rabí Samuel. Como no dejó escritos, su pensamiento lo recoge Eleazar de Worms - sobrino de aquél- en la obra
Sefer Jasidim (Libro de los piadosos). En aquellas efemérides, el cabalista es visto como protector de las masas humildes y pobres, a las cuales redime por su poder sobrenatural. Claro idealismo mesiánico. Inclusive, su prestigio llega a ser tal que se habla del "santo de Worms" y se compara con San Francisco de Asís, puesto que ambos personajes suscitaron admiración entre clases menesterosas.

Sin embargo, el postulado jasidista del desprendimiento ante los bienes terrenales, fue ignorado: el jasidismo se convirtió pronto en un poder o instrumento de magia taumatúrgica ${ }^{\circ}$.

Volvamos al tema que nos ocupa. Eleazar inaugura el concepto bomunculus o Golem mágico como culminación de la práctica cabalística. Para ello escribe recetas pertinentes: la 
mezcla de letras y prácticas mágicas, hacen que el Golem cobre vida, para convertirse en el ansiado hombre artificial. Cabe señalar aquí el poder mágico-sagrado de la 'palabra'. Está en el hombre, como en todas las cosas creadas, pero no la conoce. He aquí la noción de palabra fecundante, 'verbo' portador del germen de la creación:

"En el principio era ya el Verbo y el Verbo estaba en Dios y el Verbo era Dios"11.

Por lo tanto, el hombre debe "crear su criatura" a través de la palabra, o sea, gracias a su poder. Pese a que el hombre no conoce la palabra clave, la descubre y, amén de lo anterior, los iniciados en la Cábala consolidaron la confianza en el poder de la palabra:

"Si (como el griego afirma en el Cratilo) el nombre es arquetipo de la cosa, en las letras de rosa está la rosa y todo el Nilo es la palabra Nilo"12.

Para el cabalista, todo está encerrado en una palabra, en una palabra de cuatro letras, es el tetragramaton, el inefable nombre de Dios. Nadie reconoce la exacta invocación del Santo Nombre. Los mismos estudiosos hebreos vacilan entre Javhé y Jehovah. Veamos aspectos notorios. YHVH tiene, estudiado gemiátricamente, un valor numérico de 26: $10+5+6+10$ = 26; ésta es la cifra mágica que se repite, cual leit motiv, a lo largo de todo el Génesis. "Dios dijo: hagamos al hombre a imagen y semejanza nuestra", precisamente es el versículo 26 del primer capítulo del Génesis. Por otra parte, el cuarto capítulo - el más misterioso de todosconsta de veintiséis versículos y termina con el nombre de su autor: YHVH; también son veintiséis las generaciones que, según la Biblia, se sucedieron entre la aparición de Adán y el nacimiento de Moisés. Curiosamente, en el poema de Borges, la estrofa que alude al terrible Nombre consta de veintiséis palabras ${ }^{13}$.

Tradicionalmente se ubica el "nacimiento" del Golem en Praga, el rabino lo modela con arcilla roja -imitatio dei- magnetizada. Sobre su frente traza los caracteres de un nombre sagrado: EMETH (significa Verdad) ${ }^{14}$. De inmediato, el Golem tomaba vida. Luego, con sólo borrar la inscripción o únicamente la primera letra (METH: está muerto) la criatura quedaba inerte.
"Los judios polacos, después de pasar unos dias orando en voz alta y ayunando, moldean la figura de un hombre, en barro u otra masa viscosa, y cuando pronuncian sobre ella el nombre cabalístico de Dios, éste habría de cobrar vida. Hablar, desde luego no puede, y entender, apenas lo que se le babla u ordena. Lo llaman Golem y lo utilizan como criado para ocuparse de cualquier trabajo doméstico. En su frente figura escrita la palabra 'emeth', se desarrolla de día en día (sic) y llega a hacerse más robusto y fuerte... Les empieza a infundir espanto (a los rabinos) y le borran entonces la primera letra de la leyenda que lleva en la frente, de forma que sólo quede 'meth', al ocurrir esto se desploma y se deshace en polvo"15.

Como contraste, observemos el poema de Borges:

\begin{abstract}
"Los artificios y el candor del hombre ni tienen fin. Sabemos que hubo un día en que el pueblo de Dios buscaba el Nombre en las vigilias de la judería".
\end{abstract}

"No a la misma manera de otras que una vaga sombra insinúan en la vaga historia, aún está verde y viva la memoria de Judá León que era rabino en Praga".

"Sediento de saber lo que Dios sabe, Judá León se dio a permutaciones de letras y a complejas variaciones $y$ al fin pronunció el Nombre que es la Clave".

"El simulacro alzó los soñolientos párpados y vio formas y colores que no entendio, perdidos en rumores, y ensayó temerosos movimientos."

"El rabí le explicaba el universo (esto es mi pie; esto el tuyo; esto la soga) y logró, al cabo de años, que el perverso barriera bien o mal la sinagog $a^{\prime \prime}$.

"Tal vez hubo un error en la grafía o en la articulación del sacro nombre a pesar de tan alta becbiceria no aprendió a bablar el aprendiz de bombre".

"El rabi lo miraba con ternura y con algún horror. ¿Cómo, (se dijo) pude engendrar este penoso hijo y la inacción dejé que es la cordura?"16.

Procedamos a rescatar varios aspectos. Primero, los cabalistas infieren en un pasaje del Génesis ${ }^{17}$, que hay posibilidad de animar la materia inerte. De allí, el barro o arcilla para crear el Golem.

Ahora bien, en una cierta fase de su formación, antes de haber recibido el soplo de Dios y la palabra, Adán no sería más que un Golem 
sin forma. En un Midrash del siglo II, Adán es descrito como el Golem, Golem de grandeza y de fuerza cósmica con la que Dios se ha mostrado, en un ser sin edad y sin palabra, a todas las generaciones futuras, hasta el fin de los tiempos. Tenemos aquí un hecho sorprendente e inquietante: la mostración de la historia de la creación a un ser sin discernimiento y sin razón. En este paragón Adán-Golem, anotamos las genésicas palabras: "hasta que vuelvas a confundirte con la tierra de que fuiste formado, puesto que polvo eres, y a ser polvo tornarás." ${ }^{13}$. He aquí el alfa y la omega, el principio que es el fin, y víceversa, no es otra cosa más que el eterno retorno. Salimos de la tierra y volveremos a ella, es la restitutio ab origine, el regressus ad uterum.

En relación con el espanto que genera la criatura a su Demiurgo, el hombre, debemos referirnos a la siguiente anécdota. Fue tanta la altura alcanzada por su Golem que el rabino, para poder borrar la letra de la frente, subió atolondradamente por una escalera con tan mala fortuna que, al hacerlo, el Golem le cayó encima. Por otra parte, el rabí l.ow de Praga sufrió una experiencia igualmente espeluznante: su Golem se encolerizó, durante un oficio ritual; luego de grandes destrozos, el rabí logró arrancar el anagrama y el homúnculo quedó inactivo. Sus restos fueron depositados en un desván de la sinagoga e, igualmente, fueron considerados execrables para las generaciones futuras.

Dentro de la literatura judía y alemana, muchos autores románticos - apunta G. G. Scholem- han visto en el Golem un símbolo de los conflictos y combates que tenían en su corazón. En una novela de Gustavo Meyrink, a la que nos referiremos luego, el Golem aparece como imagen del camino hacia la redención, tal vez como probable remanente del primitivo jaisidismo soteriológico. Otros, vislumbraron en el Golem la materialización del alma colectiva del Ghetto, con el hálito sombrío de lo fantasmal; es un 'sosias' del héroe, que combate por su propia redención y que purifica mesiánicamiente a su otra parte.

\section{La tradición del homúnculo}

El concepto de homúnculo no es original ni exclusivo del jasidismo medieval. Al menos, en el contexto hebraico, se remonta a las milenarias tradiciones, a partir de los pasajes mismo del Génesis.

En el siglo XV, mediante el empleo del alambique en la generación del Golem, se hermanan la Cábala y la Alquimia. Paracelso nos habla de cómo crear un homúnculo, idea que surge de la posibilidad de engendrar un ser, de forma humana, fuera del cuerpo de la mujer, fuera de la matriz natural. Así, el esperma de varón se pudre en una calabaza (alambique) sellada con vientre putrefacto de equino. Tiempo después aparece la criatura, de la talla aproximada de un niño de diez años, la cual debe ser alimentada con sangre humana durante cuarenta semanas. Tales indicaciones se hallan contenida en Arxidoxia mágica. Observamos ostensibles variaciones: tierra y agua son sustituidos por semen virile, símbolo de la potencia de la vida, elemento fecundador por antonomasia. Por otro lado, Eleazar no precisa el dato del algún encubamiento, Paracelso sí lo explicita. Conviene señalar aquí que Paracelso también era cabalista y, notoriamente, distingue la generación, fuera del útero femenino, como un hecho de naturaleza monstruosa:

"Pues se sabe que lo que no ha sido concebido en la matriz (útero) por obra natural, tiene inclinación a lo monstruoso... no es ya semen, sino 'materia homunculi'm19.

Durante el siglo XVII acontece una desviación, en la imagen del Golem, hacia lo maligno: dotado de fuerza sobrehumana es capaz de provocar grandes calamidades e inclusive, destruir el universo. Esta concepción, como luego veremos, ha perdurado hasta nuestros días. En el contexto bíblico, lo monstruoso se asimila a lo informe, a lo caótico, a lo tenebroso, a lo abismal. Simbólicamente, es visto como modelo de regeneración: se traga o aniquila al hombre para provocar su nuevo nacimiento (palingénesis). Devora al hombre viejo para que nazca el bomo novus. De hecho, el ser devorado, deglutido o aplastado es motivo altamente frecuente en leyendas, cuentos populares y mitos. Recuérdese que el Golem es visto como figura de redención y el combate rabino-Golem revela esta prerrogativas:

'El 'ser tragado', considerado como símbolo, es un especie de descenso al mundo inferior, un volverse a hundir en el 
cuerpo de la madre, lo cual tiene por consecuencia la extinción de la conciencia; es decir, la muerte del yo al ser tragado por las tinieblas de lo inconsciente, lo cual está representado también por un símbolo de la madre terrible (voraz abismo de la muerte) (...) El descenso al Hades, la nekyia, la devoración por el animal del caos suponen tortura infernal, muerte; pero también son al tiempo, las premisas de la salvación y la resurección ${ }^{\text {nzo }}$.

La naturaleza bestial y bizarra es señalada por Borges en el poema:

"(El cabalista que ofició de numen
a la vasta criatura apodó Golem.
Estas verdades las refiere Scholem
en un docto lugar de su volumen)."

"Sus ojos, menos de bombre que de perro

$y$ barto menos de perro que de cosa

seguian al rabi por la dudosa

penumbra de las piezas del encierro".

"Algo normal y tosco bubo en el Golem

ya que a su paso el gato del rabino

se escondía. (Ese gato no está en Scholem

pero, a través del tiempo, lo adivino)"'21.

Tales motivos nutren las varias versiones cinematográficas. En 1913 y 1917 dos películas de Paul Wegener (del expresionismo alemán) retoman el tema del Golem. Su acción se lleva a cabo en Praga y la amenaza constante y latente del Golem, sobre el cual se ha perdido control, es el asunto principal. Es digno de mención aquí que estas películas y la novela de Gustavo Meyrink (Der Golem, 1915) acontecen durante la Primera Guerra Mundial, como si la técnica marcial -cual homúnculo siniestro- se volviera contra su propio creador: el hombre.

En la novela de Meyrink, el Golem es una aparición terrorífica que cada treinta y tres años se presenta detrás de las ventanas de una habitación incomunicada del gettho de Praga:

"El Golem es una figura de arcilla animada por obra de la Cábala, para defender a los judios, pero que se escapa fácilmente del control y provoca catástrofes... el Golem personifica a los autómatas humanos, que crean una sociedad moderna con sus exigencia implacables y no pueden elegir su propia esfera de acción impuesta por la propia sociedad. Lo mismo que el Golem, el hombre moderno realiza la parte a él asignada contra su propia voluntad y con su rigor atroz ${ }^{1122}$.

Pero, por supuesto, la novela de Mary Wollstonecraft Shelley, Frankenstein or The
Modern Prometheus (1818), la fabricación del hombre 'robot', da origen a una larga cadena de películas, entre los cuales podemos citar:

" 1920: "Il mostro di Frankenstein" (primera película)

" 1931: "El doctor Frankenstein" (James Whale)

* 1935: "La novia de Frankenstein" James Whale

- 1939: "El hijo de Frankenstein"(Rowlan V. Lee; estas últimas protagonizadas por Boris Karloff)

- 1942: "El fantasma de Frankenstein"

" 1957: "La maldición de Frankenstein" (interpretada por Christopher Lee)

- 1958: "La venganza de Frankenstein"

- 1969: "El cerebro de Frankenstein"

Asimismo, debe considerarse la vasta producción televisiva, que incluso se transforma de drama de terror a comedia para párvulos, con la serie "Los Monster".

En la novela de Shelley, Frankenstein es la historia de un médico que, con miembros de diversos cadáveres robados, construyó una forma humana (homúnculo), pero sin alma:

"El monstruo es muy fuerte, tiene pasiones animales y una vida activa, pero carece de 'soplo' divino... es poderoso para el mal; conocedor de sus defectos y de su deformidad, trata de hacer todo el daño posible al joven sabio que lo ha creado: Frankenstein. Y ya que $M$. W. Shelley no dio ningún nombre al monstruo, éste ha acabado por ser llamado por sus lectores con el nombre de su creador ${ }^{1123}$.

Notemos el parecido con el Golem, en cuanto a su carencia de alma o soplo divino, además de ser un producto macabro y tenebroso.

\section{Consideraciones finales}

Luego de esta inspección, el ente legendario de la Cábala materializa el ansiado sueño del hombre de ser como Dios, en cuanto a su función cosmogónica, capaz de crear vida donde no la hay. El hombre, como un modelo reducido de universo, es un microcosmos. Por tanto, ha sido "creado" con la misma esencia del cosmos: el eje estructurante o axis mundi (CIELO-TIERRA-INFIERNO). A partir de esto y tomando la característica paradigmática de 
todo mito, el hombre, mediante la iniciación -que en nuestro caso es la Cábala-, podría remontarse a ese illud tempus, el cual precede a toda creación. Empero, su obra carece de la perfección necesaria para lograr la criatura óptima; surge pues el Golem, que no posee alma ni soplo divino, visto en su incapacidad de emitir vocablos. Así el Golem simboliza la creación del hombre, que quiere imitar a Dios, creando un ser a su imagen y semejanza. La verdadera vida procede de Dios únicamente y, en su naturaleza más interna, el Golem no es otra cosa más que la imagen de su creador, la imagen de una de sus pasiones, que crece y amenaza con aplastarlo.

El elemento clave, sin duda alguna, es el poder de la palabra. Este poder se asimila a la fuerza penetrante del falo generador: el sonido audible - al igual que el trueno, la "voz del dios uránico"- penetra la oreja, matriz espiral; desciende al enrollarse en tal matriz y así fecunda el germen y crece el embrión. La palabra es el acto inicial, de ahí la terrible potencia de la maldición ${ }^{24}$.

Igualmente singular es el tema de lo tabú; el nombre de Dios es un nombre vedado, tabuado, prohibido, porque el bomo religiosus:

"Descubre el sentimiento de espanto ante lo sagrado, ante ese mysterium tremendum, ante esa maiestas que emana una aplastante superioridad de poderio; descubre el temor religioso ante el mysterium fascinans, donde se despliega la plenitud perfecta del ser"i2s.

De igual forma, hombre y Adán son imágenes de Dios, el Golem es un pobre remedo de su creador: atroz, repugnante, tenebroso y maligno. Quizás, así como Adán, el hombre sea, en parte, un Golem, puesto que una creación no puede rebasar a su autor y el hombre es como un 'aprendiz de Dios':

"En la hora de angustia y de luz vaga,

en su Golem los ojos detenia.

Quién nos dirá las cosas que sentía

Dios, al mirar a su rabino en Praga?"26.

\section{Notas}

Eliade, Mircea. La búsqueda. Buenos Aires: La Aurora, 1984, pág. 28.

Chevalier, Jean. Diccionario de símbolos. Barcelona: Herder, 1988, pág. 639. El subrayado es nuestro.
3. Borges, Jorge Luis. "El Golem", 2da estrofa. El tabú del nombre de Dios es propio de todo lo numinoso. Hay incapacidad humana de captar, en toda su extensión, lo ilimitado, lleno de ser, lo trascendente, lo 'otro'. Lo sagrado es el mysterium tremendum et fascinas, por ello es lo vedado, lo prohibido, lo tabú.

4. Scholem, G. G., La Kabbale et sa symbolique. 1960. En: Cirlot, J. Eduardo, Diccionario de símbolos. Barcelona: Labor, 1985, pág. 52.

5. Cfr. con el mito del hombre redondo y andrógino consignado por Platón en El Banquete: "Tres fueron, al principio, las clases de hombres y no dos como ahora, macho y hembra... Porque la machihembra fue, en su tiempo, una realidad visible, y con nombre común formado de ambos: de macho y de hembra... era, en total, redondo, con espalda y pechos dispuestos en círculo, con cuatro manos, con dos rostros perfectamente iguales sobre un solo cuello circular, una sola cabeza sobre ambos y opuestos rostros, cuatro orejas, dos vergüenzas y todo lo demás a tenor y semejanza con lo dicho (...) Voy, dijo (Zeus), a dividir a cada uno en dos, con lo que resultarán más débiles y útiles para nosotros, por haber crecido en número". (Platón, El Banquete, 189-90).

6. Génesis, 2, 24.

7. Borges, Jorge Luis. op. cit, 3era. estrofa.

8. Eliade, Mircea. Tratado de bistoria de las religiones. Madrid: Cristiandad, 1985, pág. 280. Honorius Augustodunengis en su Elucidarium 9s. XII) nos habla de la carne como tierra, la sangre como agua el aliento como aire, el calor como fuego. Para él, la cabeza es el cielo; el pecho, el aire; el vientre, el mar y la tierra, las extremidades inferiores. Nótese, además, el epígrafe del presente artículo. Mítica y simbólicamente, el hombre toca los tres planos cósmicos: cielo-tierra-infierno; cabeza-tronco-pies (vistos como raíces). Son harto conocidas las correspondencias, hechas por los médicos chinos, entre el hombre y el cosmos.

9. Génesis, 5, 5: "Y así todo el tiempo que vivió Adán, fue novecientos treinta años, y murió."

10. Esto es, con altos dotes para realizar prodigios de toda indole.

11. Juan, 1,1 y 5 .

12. Borges, Jorge Luis, op. cit, 1era. estrofa.

13. En el ámbito filológico, queda clara la función "cosmogónica" del logos, gran hacedor de discursos, de textos y, por tanto, de literatura y pensamiento. En griego, logos ostenta múltiples significados: vocablo, frase, discurso, razón, inteligencia, idea, sentido profundo del ser. Para los estoicos, la palabra era la razón en el orden del mundo. 
14. Nótese que se trata de un tetragramaton $y$, continuando con la reflexión acerca de la palabra, recuérdese la frase de Jesús: Yo soy el camino, la verdad y la vida, el que cree en mí no tendrá sed jamás ni morirá para siempre.

15. Grim, Jacob. Diálogo para solitarios. En: Enciclopedia Planeta de las ciencias ocultas. T. VI, Barcelona: Planeta, 1977 pág. 229. El subrayado es nuestro. Para la confección de este relato, Grim se basa en un antiguo texto talmúdico.

16. Borges, Jorge Luis, op. cit., estrofas $4,5,6,8,11,12$ y 16 respectivamente. El subrayado es nuestro.

17. Génesis, 2, 7: "Formó, pues, el Señor Dios al hombre del lodo de la tierra, e inspiróle en el rostro un soplo o espíritu de vida, y quedó hecho el hombre viviente con alma racional".

Agua y tierra, esto es la suma del elemento masculino y el elemento femenino de la creación: CIELO-TIERRA, hierogamia cósmica por excelencia, a partir de la cual surgen todas las cosas. Además recuérdese el légamo, como lugar para las hilogenias, matriz inagotable de todas las posibilidades de existencia. (Consúltese, Eliade, Mircea. Tratado de bistoria de las religiones. Capítulo VII, \#84: La pareja primordial Cielo y tierra y Capítulo V, $* 62$ : Hilogenias).

18. Génesis, 3, 19.

19. Paracelso, Pbilosopbia magna. En: Enciclopedia Planeta de las ciencias ocultas, T. VI, pág 235.

20. Jacobi, Jolande. Complejo, arquetipo y simbolo. México: F.C.E., 1983, pág. 142.

21. Borges, Jorge Luis, op. cit. estrofas 10,13 y 14 respectivamente. El subrayado es nuestro.

22. Diccionario Literario (apéndice de obras), t. I, Barcelona: Montaner y Simón S. A., 1978, pág. 537. Estas son consideraciones de Hélène Farago, crítica de literatura alemana.

23. Bompiani, Diccionario Literario, t. V. Barcelona: Montaner y Simón S. A., 1967, pág. 255. Texto de la Dra. Eugenia Beck.

24. En el Génesis, Dios crea al hombre a partir del Logos y, con ese mismo poder lo maldice (capítulo III). Igualmente, nótese en la totalidad del texto bíblico la predilección por el verbo "decir". Así como la conveción, 'todo ha sido hecho porque ha sido escrito'.

25. Eliade, Mircea. Lo sagrado y lo profano. Barcelona: Labor/Punto Omega, 1985, pág. 17.

\section{Bibliografia}

Bompiani, Diccionario literario, t. V, Barcelona: Montaner y Simón S. A., 1967

Diccionario literario (apéndice de obras) t. I, Barcelona: Montaner y Simón S. A., 1978 .

Borges, Jorge Luis, Nueva antología personal, Barcelona: Bruguera, 1985.

Brandon, S. G. F., Diccionario de religiones comparadas, 2 vol., Madrid: Cristiandad, 1977.

Castiglioni, Arturo, Encantamiento y magia, México: F. C. E., 1972.

Cirlot, Juan Eduardo, Diccionario de símbolos, Barcelona: Labor, 1985.

Chevalier, Jean y Alain Gheerbrant, Diccionario de símbolos, Barcelona: Herder, 1988.

Diccionario Steiner del ocultismo, la psiquis y lo mistico, Guayaquil: Ariel esotérica, 1975.

Eliade, Mircea, La brúsqueda, Buenos Aires: La Aurora, 1984.

Labor/Punto Omega, 1983.

na: Labor/Punto Omega, 1985.

, Tratado de bistoria de las religiones, Madrid: Cristiandad, 1985.

Enciclopedia Planeta de las ciencias ocultas, t. VI, Barcelona: Planeta, 1977.

Hutin, Serge, Historia de la alquimia, Guayaquil: Ariel esotérica, 1976.

Jacobi, Jolande, Complejo, arquetipo y simbolo, México: F.C.E., 1983.

Life goes to the movies, Boston: Time-Life books, 1975. 
Masson, Hervé, Manual-diccionario de esoterismo, México: Ed. Roca, 1975.

Platón, Dialogos socráticos, México: Cumbre, 1978.
Sagrada Biblia, Nueva York: Grolier Incorporated, 1977.

Zaniah, Diccionario estotérico, Buenos Aires: Kier, 1974. 